\title{
The vehicle takes the wheel
}

\section{Can our brains wrest control from our genes to put our own interests first?}

\author{
The Robot's Rebellion: Finding \\ Meaning in the Age of Darwin \\ by Keith E. Stanovich \\ University of Chicago Press: 2004. 374 pp. \\ $\$ 27.50, £ 19.50$
}

\section{Valerie M. Chase}

What does it mean to be rational in the modern world? The Robot's Rebellion mines evolutionary biology and cognitive science in search of an answer. Believing that "our folk psychology remains sealed off from evolutionary insights and neurophysiological facts," psychologist Keith Stanovich offers readers a sweeping tour of theory and research, advancing a programme of "cognitive reform" that puts human interests first. Who else, one may wonder, might benefit from our cognition?

An answer lurked within the theory of natural selection for more than a century before Richard Dawkins exposed it in The Selfish Gene (Oxford University Press, 1976). Living things, said Dawkins, are our genes' way of making copies of themselves. In this sense, all organisms - including humans are "gigantic lumbering robots", or "vehicles", for confederations of genes. Whereas animals sometimes behave altruistically, genes are reliably selfish. Not only do they compete mercilessly with other genes, but they sacrifice their vehicles' interests when doing so benefits their representation in the gene pool.

This gene's-eye view implies that our cognitive systems owe their existence to the genes that built us. This includes the mechanisms underlying automatic cognition, such as sensory perception and associative learning — which Stanovich refers to as the autonomous set of systems (TASS), and which laypeople might call intuition - as well as higher cognitive processes such as moral reasoning and scientific inference. To borrow Stanovich's metaphor, humans live on a long genetic "leash". As we evolved, genes endowed us with an analytic cognitive system with powers of flexible, abstract representation and reasoning that enhanced our — and crucially their — ability to survive and reproduce. In doing so, they unwittingly opened the door to the robot's rebellion. Using our analytic system, we can override TASS responses in situations where they serve the genes at our expense, much as we currently use contraception to thwart our genes' interest in having copulation lead to pregnancy.

By making the point that cognition is optimized at the level of genes, not of individuals, Stanovich puts a fresh spin on the

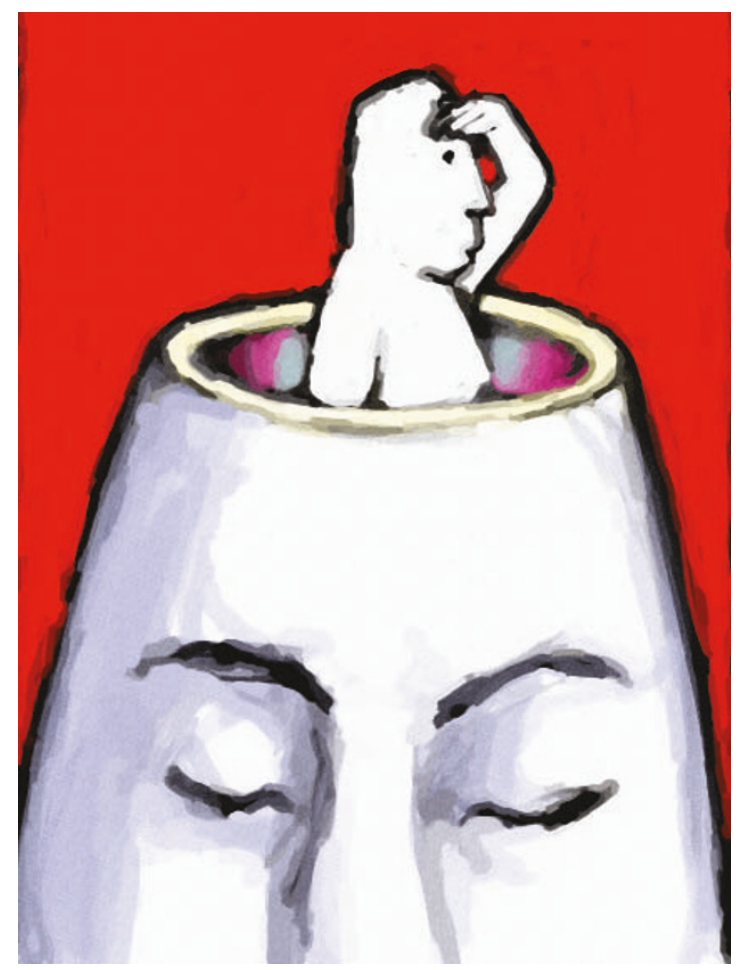

adaptive thinking be avoided?

Here Stanovich falters. One challenge for his idea of cognitive reform is defining rationality. Initially, he suggests that products of the analytic system such as logic, probability theory and utility maximization, all of which put a premium on internal consistency in choice, define what is rational. Later, he observes that inflexible adherence to these norms can undermine our interests by, for instance, causing us to violate social rules. Another challenge is figuring out how to monitor the output of TASS without overburdening the analytic system, which is slow and computationally expensive; second-guessing all our choices would be a fulltime job. To make his proposal more tractable, Stanovich might have tried systematically identifying situations where the fit between our evolved minds and familiar claim that people are sometimes woefully irrational. Selfish-gene theory also lends narrative structure to the book, which might otherwise have seemed a jumble of ideas. However, many of the self-defeating behaviours that Stanovich discusses, which include taunting disfigured people, not putting seat-belts on children and being susceptible to advertising, appear no more beneficial to our genes than to us. Our cognitive failures can often be blamed on the mismatch between the modern world and the ancestral environments in which our brains evolved, rather than on the conflict between the interests of our genes and their vehicles. Accordingly, Stanovich also draws on ideas from evolutionary psychology.

Although Stanovich emphasizes that learning can shape TASS, he maps it loosely to evolved mechanisms for solving adaptive problems such as recognizing faces, choosing a mate and reading the minds of others. As he points out, it performs such complex feats with a speed and accuracy that the serial, rule-based analytic system cannot touch. Stanovich is in awe of TASS, but warns us not to trust it blindly. Whether or not the human brain is "at war with itself", as he claims, his examples demonstrate that our intuitive cognition can prevent us from realizing today's personal and societal goals, such as maximizing investment returns and presuming innocence in criminal courts. How can these by-products of our generally our modern world is poor, and specifying how to look for and rectify blunders in each situation.

Would-be cognitive reformers receive more guidance from Stanovich concerning the rationality of their beliefs and desires. In the most thought-provoking part of the book, he argues for a definition of rationality that encompasses adherence to standards of truth and morality, as well as internal consistency. For this he takes up Dawkins' idea of memes - units of culturally transmitted information that, like genes, have no interest in their hosts except as tools for propagating themselves. Stanovich proposes, for instance, that we root out harmful memes by rigorously testing the premises behind any that encourage us to risk our physical safety, or that, like some religious and political ideologies, forbid us to evaluate them.

Sadly, evolutionary ideas have split cognitive science into pro and con camps. Like some in the con camp, Stanovich too often mistakes evolutionary psychology for a defence of the behavioural status quo. But with The Robot's Rebellion, he sets himself apart from unreflective thinkers on both sides of the divide by taking evolutionary accounts of cognition seriously, even as he urges us to improve on what evolution has wrought.

Valerie M. Chase is at the Institute of Psychology, University of Basel, Missionstrasse 60/62,

Basel 4055, Switzerland. 